\title{
Mathematics Teachers' Conceptions of Assessment: Gender and Academic Qualification Comparisons
}

\section{Bibi Mahdieh Mirian}

Department of Mathematics and Science Education, Faculty of Education, University of Malaya, 50603 Kuala Lumpur, Malaysia, mahdiehmirian@gmail.com

\section{Hutkemri Zulnaidi}

Dr., Department of Mathematics and Science Education, Faculty of Education, University of Malaya, 50603 Kuala Lumpur, Malaysia, hutkemri@um.edu.my

In recent years, many studies have focused on teachers' conceptions and their effects on instruction and learning. Accordingly, the present study aims to investigate the level of teacher's conceptions of assessment and comparison between gender and academic qualifications. It utilises a causal-comparative research design to investigate conceptions of assessment among 352 Iranian lower secondary level mathematics teachers using COA-III questionnaire. Results of the study find that math teachers exhibit moderate-level conceptions. Significant differences exist across the academic qualifications on Improvement and Irrelevance based on academic qualifications. Teachers with $\mathrm{PhD}$ qualifications have more in Improvement and Irrelevance than those with bachelor and master's degree holders. Only school accountability has significant difference between male and female teachers; male teachers exhibit more in school accountability than female teachers. Policy makers, teachers, researchers and school administrators should consider these findings in their practices to introduce and enhance alternative methods of assessment.

Keywords: accountability, assessment, conception, improvement, secondary school

\section{INTRODUCTION}

Teachers' conceptions and their influence on their decisions and actions have been the focus of substantial research for a number of years (Pajares, 1992; Woolfolk Hoy, Davis \& Pape, 2006; Fives \& Buehl, 2012). Thompson (1992) defined conceptions as reflections of 'a more general mental structure, encompassing beliefs, meanings, concepts, propositions, rules, mental images, preferences and the like'. Assessment of student learning is a vital step in teaching and learning processes. Data obtained from assessment enable teachers to reflect and make improvements on their practice. Regarding the significance of education and student learning enhancement, teachers

Citation: Mirian, B. M., \& Zulnaidi, H. (2020). Mathematics Teachers' Conceptions of Assessment: Gender and Academic Qualification Comparisons. International Journal of Instruction, 13(2), 239252. https://doi.org/10.29333/iji.2020.13217a 
must develop assessment strategies that provide essential information to make instructional enhancements. Therefore, understanding teachers' conceptions of assessment based on their different characteristics, such as years of experience or gender, is necessary.

Different beliefs and conceptions about the aims of assessment from a teacher's viewpoint can affect how new information about principles of assessment is processed or how the situations of examining, developing or selecting assessments are framed. Different conceptions about assessment may also be useful as a guideline for teachers on how they affect their decisions on other practices that they use in the classroom, such as teaching techniques and motivational strategies. In 1989, the National Council of Teachers of Mathematics (NCTM) outlined a proposal for mathematics that directed schools into the 21st century and emphasised procedural skills, real-world uses of mathematics and multi-step problem solving. Later, NCTM (2000) regarded assessment as a powerful tool for learning mathematics that can bridge the gap between teaching and learning. The aim was to improve the quality of mathematics education. Therefore, changing mathematics assessment practices in supportive ways and are in line with other ongoing changes in mathematics education was essential. In fact, any form of success in mathematics reform seemed unlikely if traditional practices had continued to dominate. Considering this issue, numerous countries started reforming mathematics education and assessment to meet the demand of 21 st century skills. Eventually, although it seemed late, the mathematics reform movement was launched in Iran in 2011.

This reform movement completely restructured the Iranian school system, revised the textbooks and fundamentally changed the educational goals in the system. It especially exhibited substantial influence on teachers' role. Similar to other reforms around the world, Iranian mathematics reformers requested teachers to serve as facilitators during mathematics teaching and learning processes, suggested teachers to grant students with opportunities to engage in conversations, which lead to solutions and asked teachers to provide substantive feedback rather than points or grades on assignments. Mathematics assessment must encompass a wide variety of methods, encourage teacher-student interaction, allow for different learning styles, promote problem-solving and selfconfidence and promote active involvement in the learning process (NCTM, 2014; Reyhani, 2015). Brown (2004) stated that teachers' conceptions influence their view and attitude with respect to assessment. Therefore, the context in which teachers understand the assessment requires consideration. Understanding how assessment is conceived by Iranian in-service mathematics teachers and how they practice assessment approaches is vital (Brown, 2002) to improve the quality of learning and teaching, ultimately improving the quality of the educational system.

Assessing student learning is a vital step in the teaching and learning processes. Data obtained from assessment enable teachers to reflect on and make improvements to their practice. Regarding the significance of education and improvement of student learning, teachers must develop assessment strategies that provide essential information to make instructional enhancements. Therefore, understanding teachers' conception of assessment based on their different characteristics such as the year of experiences or 
their gender, is necessary. Herrington, Herrington, and Glazer (2002) studied mathematics teachers and showed that teachers' conceptions mostly reflect in classroom practices and assessment. Related studies have also suggested several factors that generally act as influences or constraints to teachers' instructional practices or their implementation of alternative assessment practices in mathematics including personal and environmental factors, external pressures, culture, teachers' reflection level and teachers' experiences (Borko, Cumbo, 1993; Cooney \& Shealy, 1995; Ernest, 1988; Herrington et al., 2002).

Previous studies showed that teachers' conception of the different parts of educational process including assessment plans could affect the success of the entire educational program (Gage, 2001; Delors, 2013; Carneiro, Looney \& Vincent, 2015). Furthermore, over the past few decades, education authorities have considered the studies about the teachers' conceptions of the assessment process, especially resulting from the critique of teacher's educational process ineffectiveness, as a significant issue for teacher training (Kaiser, Südkamp \& Möller, 2017). Given the significance of the conceptions of assessment among mathematics teachers, one of the important issues in Iran is the lack of data and information about the teachers' conceptions of assessment and examinations. It is especially important in the new assessment process that focuses on improving the quality of mathematics education by modifying the learning and teaching processes focused on the use of new assessment approaches and practices. Only a few studies have investigated teachers' conceptions of assessment, specifically on the new approach; thus, information in this field is extremely limited (Kaiser, Südkamp \& Möller, 2017). Therefore, the current study aims to determine in-service Iranian mathematics teachers' conceptions of assessment at three grades of lower secondary school (7th, 8th and 9th grades) in seven educational districts. Understanding the mathematics teachers' conceptions of assessment could fill the gap between the goals of the new assessment approach of Iran's educational system and its inadequate outcomes. To the best of our knowledge, this study is the first to investigate mathematics teachers' conceptions of assessment in Iranian lower secondary schools.

This study will hopefully benefit several stakeholders in mathematics education including secondary school mathematics teachers, curriculum planners and developers in the Ministry of Education and university lecturers. Teachers may use the findings of this study to evaluate the effectiveness of the assessment, which they employ in assessing the learning process of students. Moreover, results of this study can assist the Ministry in developing courses or training programmes. The findings of this study can be used for future studies in the affective domain and assessment fields in other geographic locations and with elementary school teachers or university lecturers.

\section{Mathematics Teachers' Conception}

Defining conceptions and clearly understanding the teachers' beliefs about assessment are vital to gaining a full understanding of the model used in this study. Ausubel (1968) described conceptions as 'something that appears to us as a consequence of our concrete-empirical experiences with that very thing'. Researchers have debated that although conceptions appear to be abstract, they are not existential in nature. 
Furthermore, conceptions are deliberated as '...not knowledge or truth as philosophers or experts might look for, rather conceptions are psychologically true representations of the world, individuals or groups hold about some domain' (Ausubel, 1968). Brown (2008) asserted that 'conceptions are sometimes incomplete but are relative to each individual. Conceptions represent what individuals understand, know, believe, think, or feel about a domain at any one time'. He added that conceptions of various educational processes tend to change or affect the educational practices and outcomes of students' achievement (Brown, 2008). Pratt (1992) inferred that conceptions refer to numerous groups of thoughts held by teachers behind their explanation of how pedagogical things are experienced.

In fact, teachers see the world through the lenses of their conceptions, whilst they interpret and act according to their understanding of the world. The term 'conception' was initially introduced by Thompson (1992), with his further elaboration that conception is 'the general mental structure, encompassing beliefs, meanings, concepts, propositions, rules, mental images, preferences, and the like'. In other words, conceptions are consolidated into a unitary construct of knowledge and beliefs, which represent a subcategory of the conceptions. In the national assessment context, conceptions described the teachers' general assessment perception and awareness (Barnes, Fives \& Dacey, 2017). Brown (2002; 2004) used the term 'conception' as an 'organising framework with which an individual understands, responds to, and interacts with a phenomenon'. Brown's impression of the term 'conceptions' sees beliefs and concepts in a rather harmonious and non-conflicting manner. In this study, Brown (2002; 2004) suggested that the conception of assessment represents the teachers' understanding of how students' learning is examined, tested, evaluated or assessed. Finally, the term 'conception' is used to refer to the organised structure of ideas and beliefs about the nature and purpose of assessment (Brown, 2002). The four-factor model is as follows: 1) improvement: assessment improves the learning and teaching process, 2) school accountability: assessment holds teachers and school administrators accountable for learning, 3) student accountability: assessment holds students accountable for their learning, and 4) irrelevance: assessment is irrelevant or pernicious to the work of teachers and the lives of students. Brown's model is more relevant to this research than Newton's model because of the suitability of the former to guide the collection of data by answering the research questions. The data consist of teachers' conceptions of the assessment with regard to the different demographic information of teachers.

\section{METHOD}

\section{Research Design}

Quantitative research resign was used to investigate in-service Iranian mathematics teachers' conception of assessment at three grade levels of lower secondary school ( 7 th, 8th and 9th grades) in seven educational districts. In addition, it aims to determine whether differences in teachers' conceptions of assessment exist on the basis of two demographic characteristics of mathematics teachers, namely, gender and educational qualification. Figure 1 shows the research design of this study. 


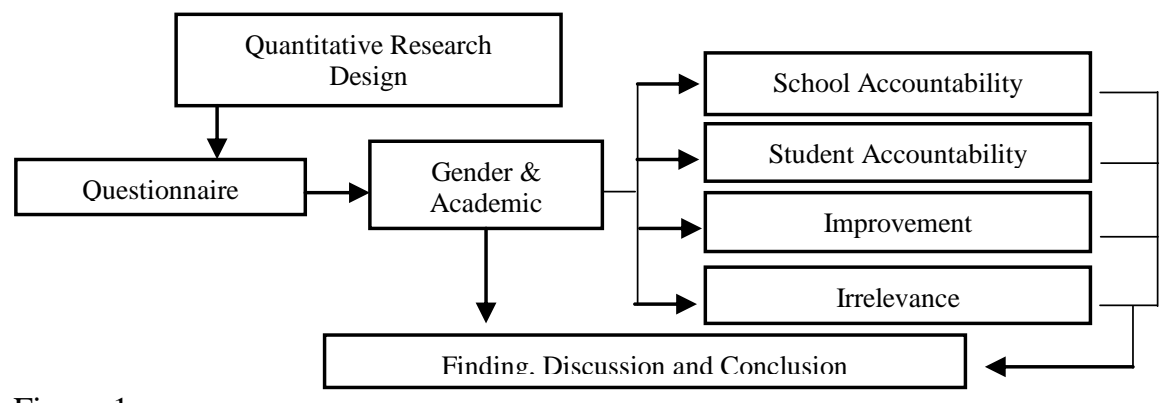

Figure 1

Research Design

\section{Participants}

A total of 352 low-level secondary mathematics teachers participated in this study. They were randomly selected from a population of 567 mathematics teachers teaching in public low-level (grades 7 to 9 ) secondary schools (female and male) during the $1^{\text {st }}$ semester of 2017-2018 in Mashhad, Iran. After obtaining permission from the Ministry of Education's Office and creating a sampling frame, the researcher used a random number generator to select the sample. The samples were randomly selected based on the sample size table by Krejcie and Morgan (1970). To avoid possible damage to the data, the researcher added $30 \%$ of the participants. Finally, to achieve an adequately huge sample size, the researcher selected and sent e-mails to all 352 teachers. All these teachers agreed to join the survey.

\section{Measures}

This study utilised a non-experimental, causal-comparative research design for data collection and data analysis. The abridged version of COA-III questionnaire comprising 27 items was used to measure teachers' conceptions related to assessment purposes. The COA questionnaire was previously validated in the Iranian context and translated into Persian (Pishghadam, Adamson \& Shayesteh, 2014; Pishghadam \& Shayesteh, 2012) . However, an expert panel of three Iranian mathematics lecturers who were experts of mathematics assessment approved the validity of the instrument used in this research. The internal consistency of all factors in the questionnaire was over 0.70, which was determined using Cronbach's alpha and was computed for each questionnaire's subcomponent. This questionnaire has two main sections. The first section contains questions regarding the teachers' gender, demographic information, academic qualification, teaching experience and grade level and the school district where they teach. The second part contains items about the teachers' theoretical assessment conceptions including 12 items for improvement, three items for student accountability, three items for school accountability and nine items for irrelevance. Items are evaluated on a six-point Likert scale (1-strongly disagree, 2-mostly disagree, 3-slightly agree, 4moderately agree, 5-mostly agree, and 6-strongly agree). The researcher gathered the data for this study via an online survey of randomly selected mathematics teachers. The link for the online survey was sent to schools, and principals were asked to ensure that all selected teachers completed the online COA-III questionnaire. A total of 50 
responses of the pilot study were submitted electronically. Consistency and reliability of each factor were more than 0.70 , which therefore enabled the researcher to interpret the scores and make a valid conclusion (Improvement: 0.89, School accountability: 0.71, Students' accountability: 0.84 and Irrelevance: 0.78) (Nunnally, 1978).

\section{Data Analysis}

Data analysis was conducted in two steps. The first step considered significant data screening-related issues, such as handling missing data, multi-collinearity and identification of outliers and normality using Statistical Package for the Social Sciences 23.0 software. Outliers were identified through a boxplot for each subconstruct. To examine normality, the skewness and kurtosis values of each item, which ranged from -1.96 to +1.96 at the 0.05 significant level (Hair, Black, Babin \& Anderson, 2010), were used. In terms of multi-collinearity, the correlation among factors should be less than 0.90 (Kline, 2005). For the second step, a comparison using One-Way MANOVA test was utilised to identify conception of assessment factors by gender and academic qualification (Pallant, 2016).

\section{FINDINGS}

\section{Mathematics Teachers' Conceptions of Assessment Level}

The descriptive statistics, which included mean score and standard deviation for four factors and items in the current survey, was used to identify the mathematics teachers' conceptions of assessment among Iranian lower secondary school mathematics teachers in Mashhad.

\section{Table 1}

Descriptive Statistics of Mathematics Teachers' Conceptions of Assessment (MTCoA)

\begin{tabular}{lcc}
\hline Mathematics Teachers' conceptions of assessment & M & S D \\
\hline Student Accountability (STACC) & 4.02 & 0.72 \\
School Accountability (SACC) & 3.89 & 0.74 \\
Improvement (IMP) & 3.57 & 0.45 \\
Irrelevance (IRR) & 3.49 & 0.51 \\
\hline
\end{tabular}

Table 1 shows that student accountability $(M=4.02, S D=0.72)$ had the highest agreement level followed by school accountability $(M=3.89, S D=0.74)$. The two conceptions were not generally different, and participants were more likely to answer 'Moderate Agreement' level among other variables. Meanwhile, irrelevance conception $(M=3.49, S D=0.51)$ had the smallest mean, whereas the other remaining conception is improvement $(M=3.57, S D=0.45)$. Thus, these two conceptions could be considered around 'Slight Agreement' level among other variables.

\section{Comparison of Mathematics Teachers' Conceptions of Assessment based on Gender}

Multivariate analysis of variance (MANOVA) was conducted to determine whether any significant difference exists among different conceptions of assessment with respect to gender. The homogeneity of variance-covariance matrices as calculated by Box's $\mathrm{M}$ test was (Box's $M=11.58, F=1.14, p=0.32$ ). Therefore, the variances were approximately equal; the homogeneity of variance of dependent variables exists among 
the groups. The results of Wilk's Lambda showed no significant difference effect of gender on the dependent variable in four dimensions: $\mathrm{F}(4,347)=1.24$, Wilks Lambda $=0.98, \mathrm{p}=0.29(p>0.05)$.

Table 2

Results of a One-Way MANOVA on the Difference in Conception of Assessment Factors based on Gender

\begin{tabular}{lllllll}
\hline Dependent Variable & Type III Sum of Squares & Df & MS & F & P & $\eta^{2}$ \\
\hline School accountability & 2.196 & 1 & 2.19 & 4.03 & 0.04 & 0.011 \\
Student accountability & 0.897 & 1 & 0.89 & 1.69 & 0.19 & 0.005 \\
Improvement & 0.171 & 1 & 0.17 & 0.81 & 0.36 & 0.002 \\
Irrelevance & 0.060 & 1 & 0.06 & 0.22 & 0.63 & 0.001 \\
\hline
\end{tabular}

Mathematics teachers' conception of assessment reported similar results in three dimensions with respect to gender (refer Table 2). Student Accountability $F=(1,350)=$ 1.69, $p=0.19(p>0.05)$, Improvement $F=(1,350)=0.17, p=0.36(p>0.05)$, Irrelevance factor $F=(1,350)=0.22, p=0.63(p>0.05)$. However, results showed that significant differences exist across gender on School Accountability $F=(1,350)=2.16$, $p=0.04(p<0.05)$. When mean scores for School Accountability conception were compared between male and female, result showed that Male mathematics teachers $($ Mean $=4.08)$ exhibited higher level than female mathematics teachers' $($ Mean $=3.98)$ conception of assessment as a process of School Accountability. The values of Partial eta-squared shown for each dimension of teachers' conception of assessment as follows (School Accountability $=0.011$, Student Accountability $=0.005$, Improvement $=0.002$, Irrelevance $=0.001$ ) present that all factors have low effect size. Cohen 's (1988) guidelines indicated that the level of effect size with less than 0.3 denotes low effect, whereas that between 0.3 and 0.8 shows moderate effect size and more than 0.8 shows high effect size.

\section{Comparison of Mathematics Teachers' Conceptions of Assessment based on Academic Qualifications}

MANOVA was conducted to determine whether any significant differences exist among different conceptions of assessment with respect to academic qualification. The homogeneity of variance-covariance matrices, as calculated by Box's M test is (Box's $M=17.29, F=0.83, p=0.66)$. The results showed significant difference effects of academic qualification on dependent variable in four dimensions: $F(8,692)=3.65$, Wilks Lambda $=0.92, p<0.05$; partial $\eta 2=0.04$. Mathematics teachers' conception of assessment reported similar results in two dimensions of conception with respect to academic qualification (refer Table 4). Specific values are School Accountability $F=$ $(2,349)=1.72, p=0.17(p>0.05)$, Student Accountability $F=(2,349)=1.48, p=0.06$ $(p>0.0125)$. However, significant differences exist between academic qualification and Improvement, $F(2,349)=4.47, p<0.05$, partial $\eta 2=0.02$ and Irrelevance, $F(2,349)=$ 6.42, $p<0.05$, partial $\eta 2=0.03$. The Scheffe test results showed that only $\mathrm{PhD}$ and master's degree holders were significantly different in irrelevant conception (Mean difference $=-0.34, \mathrm{p}<0.05)$. Degree qualification of teachers with master's qualification conceived that assessment is unfair and irrelevant. 
Table 3

Results of a One-Way MANOVA on the Difference in Conception of Assessment Factors by Academic Qualification

\begin{tabular}{lllllll}
\hline Dependent Variable & Type III Sum of Squares & Df & MS & F & P & $\eta^{2}$ \\
\hline School accountability & 1.88 & 2 & 0.94 & 1.72 & 0.17 & 0.010 \\
Student accountability & 2.96 & 2 & 1.48 & 2.83 & 0.06 & 0.016 \\
Improvement & 1.84 & 2 & 0.92 & 4.47 & 0.01 & 0.025 \\
Irrelevance & 3.32 & 2 & 1.66 & 6.42 & 0.00 & 0.036 \\
\hline
\end{tabular}

In addition, the results showed that only Master's and degree qualifications in improvement conception were significantly different (mean difference $=-0.15, \mathrm{p}<$ 0.05). By contrast, teachers with Master's qualification conceived more that assessment improves teaching and learning mathematics than degree qualification holder. The value of Partial eta-squared shown for each dimension of teachers' conception of assessment (School Accountability $=0.01$, Student Accountability $=0.01$, Improvement $=0.02$, Irrelevance $=0.03$ ) presents that all factors have low effect size

\section{DISCUSSION}

This study aims to investigate in-service Iranian mathematics teachers' conceptions of assessment at lowest three grades of the secondary school levels (7th, 8th and 9th grades) in seven educational districts in Mashhad, Iran. The results of the analysis of the means and standard deviations related to the level of agreement in mathematics teachers' conceptions about assessment purposes confirmed that student accountability conception had the highest agreement level, which was followed by school accountability conception. The two conceptions were not generally different, and participants were likely to answer 'Moderate Agreement' level among other variables. By contrast, the irrelevance conception that had the smallest mean as well as the improvement conception could be considered around the 'Slight Agreement' level among other variables. Therefore, mathematics teachers mostly conceived that assessment further renders the school and students accountable. This finding suggests that mathematics teachers at lower secondary government schools in Mashhad conceived assessment purpose in relation to accountability (student and school) rather than improvement. This result was initially expected given the culture of accountability under the Iranian educational system.

This finding might be explained by the fact that the nature and culture of Iranian educational system are more grading-oriented rather than learning-oriented (Saad, Sardareh \& Ambarwati, 2013) particularly in mathematics, which has long been considered a top priority in Iranian school curricula since decades before. The competitive nature of the educational system encourages this idea and belief that a good student is the one who obtains good scores because the examination results reflect the quality and worth of the individual. Summative assessment approach or traditional assessment approach has been mostly used in this educational system for a long time; therefore, the final score becomes the ultimate goal in the educational system. In fact, Iranian society considers assessment as marks or grades. Assessing students in secondary school has been difficult owing to their judgment that only marks or grades are important. Thus, if a student acquired a good grade, then, everybody supposes that 
this student is eligible to enter a university (Saad et al., 2013). This notion encourages students to exert further effort to obtain higher grades at school and in nationwide examinations. Moreover, high stake assessments have a considerable effect on how students shape their future plans; teachers seriously undertake the responsibility to prepare their students for such examinations, hence helping their students obtain higher scores than others.

The findings of the current study are consistent with the results of the study on teachers' conceptions of assessment in the Chinese context (Brown \& Gao, 2015). Researchers found that teachers conceived accountability purpose more than improvement. Indeed, in high-stakes environment, such as China and Iran where examination results determine placement into different levels of education and acceptance into high-quality institutions, teachers frequently use summative assessment to motivate students and provide instruction in the classroom. Thus, teachers are expected to endorse assessment aimed at the accountability of schools and students. Earl and Timperley (2014) studied among two groups of secondary mathematics teachers in the United States and also found that the first group of mathematics teachers who participated in the study followed the traditional conception of assessment (test-oriented assessment). However, the smallsized sample in this study reduced the possibility of generalising the results achieved to the entire population of mathematics teachers in the United States (Earl \& Timperley, 2014).

The findings of this study showed that significant differences accrued between academic qualification and mathematics teachers' conception of assessment in two categories (irrelevance, improvement). Based on the results, mathematics teachers with Ph.D. degree conceive more that assessment is unfair and irrelevant than mathematics teachers with MA or BA degrees. Moreover, the results showed that teachers with MA conceive more that assessment improves teaching and learning mathematics than those who hold BA or Ph.D. degrees. The outcomes of studies on the effect of teachers' academic qualification on their conception of assessment are not the same. Brown's study implies that teachers' academic qualification has no significant effect on teachers' conception of assessments. Therefore, unlike the other personal variables in this study (gender, experience and grade taught), the findings of the current study regarding the effects of the teachers' academic qualification on their conception of assessments are not supported by Brown's model. Most of the previous studies in this area believed that the teachers' academic qualification is a significant factor with regard to the conception of assessment among teachers. For example, the results of the current study with regard to the impact of teachers' academic qualification on their conception of assessment is supported by the outcomes of a study by Pishghadam and Shayesteh (2012) on teachers' conception of assessment among the Iranian English teachers in private language institutes. They showed that most of the participants with $\mathrm{PhD}$ degrees (compared with the teachers with MD or BA degrees) believed that the assessments are irrelevant. However, this study contradicts that of Barnes, Five and Dacey (2017), who found no significant difference on teachers' conception based on academic qualification. In other words, participants with high level of education mostly believed that the assessment is something bad or unfair (Pishghadam \& Shayesteh, 2012). 
The researchers pointed the significance of objective measurement in Iran's educational system. Therefore, several teachers with Ph.D. degrees believe that an assessment may be inaccurate and inexact, and margin for errors constantly occur. Less quality of assessment courses in universities or absence of assessment courses in universities might be another possible reason (Pishghadam \& Shayesteh, 2012). Notably, both reasons may explain the results of the current study. Furthermore, a study by Calveric (2010) about teachers' assessment conception and practices among 79 teachers confirmed that significant relationships existed between conception and practices related to the level of degree attainment or academic qualification of teachers. Findings showed that significant differences were identified between teachers who earned Bachelor's degrees and those who earned postgraduate certificates and Master's degrees in the mean score for student accountability assessment conception. Calveric (2010) suggested that this finding was related to teachers' inadequate levels of assessment literacy and professional development related to assessment.

The result of the study showed that significant differences did not accrue between gender and mathematics teachers' conception of assessment, which means that female and male mathematics teachers similarly conceived the purpose and nature of assessment. However, the result showed that significant differences exist across the gender on School Accountability conception. Male mathematics teachers conceived assessment more as a process of School accountability than female mathematics teachers when mean scores were calculated. The main probable reason why gender factors are no longer underlined as a facet of variables influencing mathematics teacher conception among male and female teachers is that mathematics teachers are working under the same education policy and education culture. Even after the reform movement and when new mathematics curricula was introduced, the system of education in Iran remains to be a teacher-centred system, wherein teachers exhibit the most authority and responsibility (Moiinvaziri, 2015). Classes are typically held as lectures by teachers, and students are mostly passive. Thus, teachers' gender would not be a concern because all teachers including female and male follow the same goal, which is the accountability of schools and students. In other words, all teachers (female and male) adapt to local guidelines developed for accountability standards; consequently, learning assessment skills are necessary to assist them whilst they prepare students for academic success on national assessments. Brown's studies implied that gender is not a determinant factor in teachers' conception of assessment. By contrast, Evans and Waring (2011) found the effect of gender to assessment feedback. Females hold a larger part of the assessment feedback on the task than males. Therefore, the findings of the current study (regarding gender difference) are supported by Brown's model of conception of assessment. However, reviewing the studies related to the relationship between gender and teachers' conception of assessment shows that these studies have reached dissimilar findings in general. Several studies reported no effect between the relationship of gender and conception of assessment among the teachers, whereas some studies supported the significant effect of gender on the teachers' conception of assessment.

The results of the current study are consistent with a study by Barnes et al. (2017). It was conducted in the United States, which considered the teachers' conceptions of the purposes of assessment. Their findings suggest that no significant difference between male and female participants exists in terms of their conceptions of assessment (Barnes et al., 2017). In another example, a study by Moiinvaziri (2015), involving 147 Iranian teachers in Sirjan 
universities, reported no significant relationship between conceptions of assessment and gender among the participants (Moiinvaziri, 2015). Moreover, Benson (2014) conducted a study among middle school teachers in the United States regarding the differences between teachers' conceptions of assessment in terms of the demographic characteristics. The findings indicated that the gender of the respondents did not yield any significant difference in their conceptions of assessment. According to the researcher, one of the possible reasons for this finding could be the requirements set for teachers (regardless of their gender) to follow the federal, state or local accountability guidelines in assessing student performance. As mentioned above, some studies reported that teachers' conception of assessment was influenced by their gender. To illustrate, the findings of a study by Ndalichako (2015) in Tanzania secondary schools showed that a significant difference exists in the conception of assessment between male and female teachers who participated in the study. Females were found to have more desirable conception of assessment than males (Ndalichako, 2015).

Ensuring that schools do not push teachers to enact teaching and assessment practices that fail to reflect the reform intent of preparing students for real life is vital for policy makers and the ministry of education. The absence of improvement conception in assessment as a first level of agreement in this study suggests that numerous teachers' assessment practices reflect the policy only to the latter. Such enactment is a 'cultural morphing', which is a way teachers and stakeholders incorporate reforms within the existing cultural norms (Goh \& Wong, 2013). In such instances, superintendents or policy makers must help the schools' leadership teams understand the philosophies underlying the policy, to comprehend the reform goals and to review ways aligned with their school-based processes and procedures with the reform vision. More importantly, policy makers and school leaders could provide increased open communication channels and revision policies based on consultation with and feedback from teachers. In fact, if policy makers want to bring about changed practices, they must work with teacher educators to facilitate teachers' comprehension and interpretation of their beliefs and values prior to and during a reform effort. Adopting constructivist approaches means allowing a larger student presence in the classroom; thus, this change in classroom dynamics may be uncomfortable for teachers who hold the notion that 'authority is hierarchy', and 'classroom talk is teacher dominated'(Hogan, 2014). Teaching practices in Iran are embedded in the deep cultural traditions of the Asian region as a whole. Therefore, teacher educators and policy makers must help teachers reconcile western-style approaches with traditional Asian views of teaching and learning to ensure further alignment to the spirit of the reform (Goh \& Wong, 2013).

The findings of this study provide implications for teachers because teachers' conceptions play an important part in mediating how educational reforms are implemented in schools and classrooms. Teachers should know that the way they conceive of assessments shapes the way they utilise the results of assessments and frames their selection and development of assessment tools in their classrooms (Brown, 2008). This study implies that teachers must change their conceptions to help improve student achievement in mathematics. They must use other alternative assessments that would engage students in the process of learning. Working towards changing the nature of large-scale assessments and thus enabling the assessment of a larger range of skills and cognitive domains would be useful for researchers. The findings of this study also have implications for principals at schools, given that they decide for schools' curricular programs and approve the types of support and resources that teachers require to bring about student learning. In this study, teachers showed that they 
agree with school accountability as a second conception of assessment, which means that assessment holds teachers, schools and systems accountable for achieving societal goals and expectations. Moreover, assessment results are used to publicly demonstrate that teachers and schools are performing well. Schools and teachers are rewarded (e.g., pay bonuses) or punished (e.g., dismissal) for exceeding or not reaching the required standards. This conception of assessment by teachers provided evidence that school level policies have created a culture that is misaligned with the reform objectives and vision. Therefore, an urgent need for principals to be mindful of the effect of school-level policies on teachers' assessment practices is necessary, especially if they detract from the policy intent. For example, principals must move beyond being administrative consumers of assessment data to enhance student learning; rather, they must be equipped with assessment literacy skills so that they can lead their staff in interpreting, evaluating and analysing assessment data together (Stiggins, 2001). Future research might be done to identify mathematics teachers 'conception of teaching, learning and mathematics curriculum and how they are related to the conception of assessment.

\section{CONCLUSION}

This study has shown that mathematics curriculum reform alone does not guarantee changes in the nature of assessment without changing the conceptions of mathematics teachers regarding its purposes. To implement a revised curriculum, the conceptions held by teachers should be matched with the curriculum ideas as previously mentioned that teachers play a key role in driving educational reform movement. The study demonstrated that majority of teachers had an accountability conception about the nature and purpose of assessment, which are not aligned with the curriculum. Generally, their conceptions did not reflect improvement conception. Assessment was very effective on teachers' pedagogical practice and was associated with most of the other factors such as teacher accountability for students' results and schools and policy makers' pressure for a score-oriented culture. Finally, owing to the lack of data and limited studies on Iranian mathematics teachers' conception with respect to assessment, this study has provided information on a large scale among Iranian mathematic teachers, which would be beneficial not only for Iranian mathematics researchers but also for all mathematics researchers worldwide.

\section{REFERENCES}

Ausubel, D. P. (1968). Educational psychology: A cognitive view. NY: Holt.

Barnes, N., Fives, H. \& Dacey, C. M. (2017). U.S. teachers' conceptions of the purposes of assessment. Teaching and Teacher Education, 65, 107-116.

Borko, H. Flory, M., \& Cumbo, K. (1993). Teachers' ideas and practices about assessment and instruction: A case study of the effects of alternative assessment in instruction, student learning, and accountability practices. Paper presented at the Annual Meeting of the American Educational Research Association, Atlanta, GA.

Brown, G. T. L. (2002). Teacher conceptions of assessment (Unpublished Doctoral Dissertation). University of Auckland, Auckland, New Zealand.

Brown, G. T. L. (2004). Teachers' conceptions of assessment: implications for policy and professional development. Assessment in Edu Prin, Pol \& Prac, 11(3), 301-318.

Brown, G. T. L. (2008). Conceptions of assessment: Understanding what assessment means to teachers and students. New York, NY: Nova Science. 
Brown, G. T. L., \& Gao, L. (2015). Chinese teachers' conceptions of assessment for and of learning: Six competing and complementary purposes. Cogent Education, 29(1), 993836. https://doi.org/10.1080/2331186X.2014.993836.

Calveric, S. B. (2010). Elementary teachers' assessment beliefs and practices (Upublished doctoral dissertation). Virginia Commonwealth University, Virginia, USA.

Carneiro, R., Looney, J., \& Vincent-Lancrin, S. (2015). Learning from the past, looking to the future: Issues and agendas in education. European J. of Edu., 50(4), 524-535.

Cohen, J. (1988). Statistical power analysis for the behavioral sciences. Hillsdale, NJ: Lawrence Earlbaum Associates.

Cooney, T. J. \& Shealy, B. E. (1995). Teachers thinking and rethinking assessment practices. Paper presented at the Annual Meeting of the North American Chapter of the International Group for the Psychology of Mathematics Education. Columbus, $\mathrm{OH}$.

Delors, J. (2013). The treasure within: Learning to know, learning to do, learning to live together and learning to be. What is the value of that treasure 15 years after its publication? International Review of Education, 59, 319-330.

Earl, L. \& Timperley, H. (2014). Challenging conceptions of assessment. In C. Wyatt-Smith, V. Klenowski, \& P. Colbert (Eds.), Designing assessment for quality learning (pp. 325-336). Dordrecht, The Netherlands: Springer.

Ernest, P. (1988). The impact of beliefs on the teaching of mathematics. Paper Prepared for ICME VI, Budapest, Hungary.

Evans, C., \& Waring, M. (2011). Enhancing feedback practice: A personal learning styles pedagogy approach. In S. Rayner, \& E. Cools (Eds.), Style differences in cognition, learning and management: Theory, research and practice (pp.188-203). New York: Routledge.

Fives, H., \& Buehl, M. M. (2012). Spring cleaning for the "messy" construct of teachers' beliefs: What are they? which have been examined? What can they tell us? In K. R. Harris, S. Graham, \& T. Urdan (Eds.), APA educational psychology handbook, Vol 2: Individual differences and cultural and contextual factors (pp.471-499). Washington, DC: APA. http://dx.doi.org/10.1037/13274-000.

Gage, N. L. (2001). The scientific basis of the art of teaching. [M. Mehrmohammadi, Trans.]. Tehran: School Publishing. [In Persian].

Goh, C. L., \& Wong, T. (2013). Bridging the education gap. The Straits Times, pp. 2-3.

Hair, J. F., Black, W. C., Babin, B. J., \& Anderson, R. E. (2010). Multivariate data analysis. Englewood Cliffs, NJ: Prentice Hall.

Herrington, A., Herrington, J., \& Glazer, E. (2002). Authentic approaches to learning assessment strategies: Beginning teachers' practices in classrooms. Proceedings of the International Group for the Psychology of Mathematics Education. Athens, GA.

Hogan, D. (2014). Why is Singapore's school system so successful, and is it a model for the West? Retrieved from http://theconversation.com.

Kaiser, J., Südkamp, A., \& Möller, J. (2017). The effects of student characteristics on teachers' judgment accuracy: Disentangling ethnicity, minority status, and achievement. Journal of Educational Psychology, 109(6), 871. 
Kline, R. B. (2005). Principles and practice of structural equation modeling. Methodology in the social sciences. New York: The Guilford Press.

Krejcie, R., \& Morgan, D., (1970). Determining sample size for research activities. Educational and Psychological Measurement, 30, 607 - 610.

Moiinvaziri, M. (2015). University teachers' conception of assessment: A structural equation modeling approach. J. of Language, Linguistics and Literature, 1(3), 75-85.

NCTM. (1989). Assessment standards for school mathematics. Reston. VA: NCTM.

NCTM. (2000). Principles and standards for mathematics. Reston, VA: NCTM.

NCTM. (2014). Principles to action: Ensuring mathematical success for all. NCTM.

Ndalichako, J. L. (2015). Secondary school teachers' perceptions of assessment. Int. J. of Inf. and Edu. Tec., 5(5), 326-330. https://doi.org/10.7763/IJIET.2015.V5.524.

Nunnally, J. C. (1978). Psychometric theory. New York, NY: McGraw-Hill.

Pajares, M. F. (1992). Teachers' beliefs and educational research: Cleaning up a messy Construct. Re of Edu Res, 62(3), 307-332. https://doi.org/10.3102/00346543062003307.

Pallant, J. (2016). SPSS survival manual: A step by step guide to data analysis using SPSS program. London, UK: McGraw-Hill Education.

Pishghadam, R., Adamson, B., \& Shayesteh, S. (2014). Conceptions of assessment and teacher burnout. Asses. in Edu. Prin., Pol. \& Prac, 21, 34-51.

Pishghadam, R., \& Shayesteh, S. (2012). Conceptions of assessment among Iranian EFL teachers. The Iranian EFL Journal, 8(3).

Pratt, D. D. (1992). Conceptions of teaching. Adult Edu. Quarterly, 42(4), 203-220.

Reyhani, E. (2015). Analysis of policy documents approved, reputable research and resources related to the field of mathematics. Research, Development and Mathematical Education in Persian Language.

Saad, M. R. B. M., Sardareh, S. A., \& Ambarwati, E. K. (2013). Iranian secondary school EFL teachers' assessment beliefs and roles mohd. Life Sci. J., 10(3), 1638-1647.

Stiggins, R. J. (2001). The principal's leadership role in assessment. NASSP Bulletin, 85(621), 13-26.

Benson, III, T. P. (2014). Sixth through eighth grade teachers' conceptions (beliefs) about assessment and practices (Unpublished doctoral dissertation). Wingate U.

Thompson, A. G. (1992). Teachers' beliefs and conceptions: A synthesis of the research. In D. A. Grouws (Ed.), Handbook of research on mathematics teaching and learning (pp. 127146). New York: MacMillan.

Woolfolk Hoy, A., Davis, H., \& Pape, S. J. (2006). Teacher knowledge and beliefs. In P. A. Alexander, \& P. H. Winne (Eds.), Handbook of educational psychology (pp. 715-737). Mahwah, NJ: LEA. 